\title{
Growing bone cysts in long-term hemodialysis
}

\author{
J.L. Gielen, M.D. ${ }^{1}$, M.T. van Holsbeeck, M.D. ${ }^{1}$, D. Hauglustaine, M.D. ${ }^{2}$, L. Verresen, M.D. ${ }^{2}$, E. Verbeken, M.D. ${ }^{3}$, \\ A.L. Baert, M.D. ${ }^{1}$, L. Meeus, M.D. ${ }^{4}$, P. Vandevoorde, M.D. ${ }^{4}$, P. Michielsen, M.D. ${ }^{5}$, and A. Coral, M.D. ${ }^{6}$ \\ ${ }^{1}$ Department of Radiology, ${ }^{2}$ Department of Nephrology, ${ }^{3}$ Department of Pathology, \\ University Hospitals, K.U. Leuven, Belgium \\ ${ }^{4}$ Department of Radiology, ${ }^{5}$ Department of Pathology, Algemeen Ziekenhuis ST Jan Brugge, Belgium \\ ${ }^{6}$ Department of Radiology, University of Michigan Hospitals, Ann Arbor, Michigan, USA
}

\begin{abstract}
All patients with chronic renal failure undergoing hemodialysis for more than 10 years in the university hospitals of Leuven were selected for this study. The medical records and radiographs of these 21 patients were studied retrospectively. Skeletal surveys were examined for the presence and location of subchondral cysts. The predialysis films and the films taken after 5,10 , 15 and 20 years of dialysis were reviewed. Subchondral cysts that grew in size and number were found in the wrist, humeral head, hip, and patella. Accurate measurements were made of cysts in the wrist and compared with a control group. In the dialysis group, cystic involvement of the wrist was more common and the size and number of the cysts were larger. Soft tissue swelling was seen in the dialysis group but not in controls. Soft tissue swelling was assessed on shoulder radiographs by measuring the acromiohumeral distance (ACD) and in the knees by ultrasonic measurement of synovial thickness [25]. In 11 patients synovial or bone biopsies or aspirated synovial fluid were available. All these patients had swollen joints and multiple subchondral periarticular cysts. Amyloid deposition was found in ten of these patients, and this proved to be composed of B2 microglobulins in seven (Table 1).
\end{abstract}

Key words: Bones - amyloidosis - Bones, cysts - Bones, primary metabolic abnormalities - Dialysis

There are few descriptions of the radiographic picture of bone and joint amyloid in the literature and only a few patients with this condition have been reported to date $[2,8,10,12,15,21,22,27]$. These descriptions appeared first in the 1960s and 1970s; since the early 1980s there have been increasingly frequent reports of bone and joint amyloid in patients with renal disease

Address reprint requests to: J.L. Gielen, Department of Radiology, University Hospitals K.U. Leuven, Herestraat 49, B-3000 Leuven, Belgium in the rheumatologic and renal journals $[1,3,4,6,7$, $9,13,14,16,19,26,28]$.

Intra-osseous amyloid of the type found in patients on long-term hemodialysis is a new form of the disease characterized by the presence of B2-microglobulin. The few radiological reports of this new form describe lesions which are similar to other previously reported cases of amyloid in bone. The condition is likely to be widespread and common in centers using cuprophane membranes for long-term hemodialysis [7, 9, 24].

Radiographic signs of bone and joint amyloid were sought in patients who had been on long-term dialysis and the frequency of amyloid in our dialysis population was measured. The criteria used were: (1) subchondral cysts, (2) large punched-out erosions, and (3) periarticular soft tissue swelling $[11,26]$. The diagnosis was confirmed by biopsy or aspiration of involved joints.

\section{Materials and methods}

The skeletal surveys of 21 patients (Table 1) taken at the start of dialysis and at 5-year intervals thereafter were viewed retrospectively. The predialysis films of 19 patients and the films after 5 and 10 years of dialysis in 20 patients were available. Eight patients had dialysis for more than 15 years and one for over 20 years.

A skeletal survey consisted of films of chest, skull, spine, pelvis, wrists, hands, acromioclavicular joints, shoulders, feet, ankles, tibias, knees, and femurs. The 5-yearly radiographic data in each patient were mapped out to give a visual display of disease progression (Fig. 1). Serial films during the total period of dialysis were available in 21 patients.

The two wrist control groups were outpatients of the department of Rheumatology who were having measurements done for bone mineral content. Asymptomatic individuals only were included in these control groups. We carefully examined the films of the wrists of these patients for the presence of cystic lesions which were defined as subchondral lucent lesions larger than $1 \mathrm{~mm}$ in size with a surrounding sclerotic margin. The lucent areas of $1 \mathrm{~mm}$ and less were interpreted to be vascular channels [29]. The smallest cross-sectional diameter of all the wrist cysts was measured by two radiologists independently (J.G. and M.v.H.). They examined PA wrist films which were taken every 5 years. The measure- 
Table 1. Overview of the clinical, radiological and pathological findings in 21 patients

\begin{tabular}{|c|c|c|c|}
\hline Patient & $\begin{array}{l}\text { Growing cysts } \\
\text { seen on X-ray }\end{array}$ & Clinical & Pathological \\
\hline A.J. & Hip L & Negative & CL biopsy \\
\hline B.L. & $\begin{array}{l}\text { Hips, wrists, } \\
\text { patellas, } \\
\text { dist. rad. L }\end{array}$ & $\begin{array}{l}\text { Shoulder L } \\
\text { Wrists }\end{array}$ & CL biopsy \\
\hline Bx.L. & Wrist L & Negative & \\
\hline C.M. & Negative & Negative & \\
\hline D.A.M. & Wrists, patella $\mathrm{R}$ & Knees & Knee asp ${ }^{a}$ \\
\hline D.K. & Hip R, wrists & Hip R & $\begin{array}{l}\text { CL, carpal } \\
\text { cyst and } \\
\text { synovial } \\
\text { biopsy }\end{array}$ \\
\hline D.P.J. & $\begin{array}{l}\text { Shoulders } \\
\text { Hip R, Wrists }\end{array}$ & Diffuse & $\begin{array}{l}\text { Hip } \\
\text { resection } \mathrm{R}\end{array}$ \\
\hline G.G. & $\begin{array}{l}\text { Hips, wrists } \\
\text { Patella R, } \\
\text { radial head R }\end{array}$ & Negative & \\
\hline G.M. & $\begin{array}{l}\text { Hip R, MCP joints, } \\
\text { wrist } R\end{array}$ & Negative & \\
\hline J.A. & $\begin{array}{l}\text { Ulna L, hip L, } \\
\text { head humerus R }\end{array}$ & Hip L, knees & Knee asp \\
\hline J.R. & $\begin{array}{l}\text { Shoulders, hips, } \\
\text { wrist R }\end{array}$ & Negative & \\
\hline L.D. & $\begin{array}{l}\text { Hips, patella L, } \\
\text { femoral condyle } L\end{array}$ & All joints & Knee biopsy \\
\hline L.P. & Shoulders, wrists & Shoulders & \\
\hline M.Th. & $\begin{array}{l}\text { Shoulders, } \\
\text { hips, patellas }\end{array}$ & $\begin{array}{l}\text { Shoulders, } \\
\text { knees }\end{array}$ & Knee asp. \\
\hline N.A. & Negative & Negative & \\
\hline R.E. & $\begin{array}{l}\text { Shoulder R, } \\
\text { hip R }\end{array}$ & Hip R, wrists & CL biopsy \\
\hline S.L. & Wrist $\mathbf{L}$, tibia $\mathbf{L}$ & $\begin{array}{l}\text { Shoulders, } \\
\text { knee R }\end{array}$ & \\
\hline V.A.A. & Hips, wrists & Hips, neck & \\
\hline V.B.C. & Wrists & $\begin{array}{l}\text { Shoulder } R \text {, } \\
\text { wrist } L \text {, knees }\end{array}$ & Knee asp. \\
\hline V.E. & $\begin{array}{l}\text { Wrists, hips, } \\
\text { shoulder R }\end{array}$ & $\begin{array}{l}\text { Wrist R, } \\
\text { shoulders, knees }\end{array}$ & Knee biopsy \\
\hline V.Y. & Wrists & Negative & \\
\hline
\end{tabular}

R: Right; L: left; CL: carpal ligament; Asp: joint aspiration a Knee aspiration negative for amyloid. All pathologic specimens of the other patients were positive for amyloid

ments were compared: inter-observer differences were never greater then $1.0 \mathrm{~mm}$ and any increase in cyst diameter was noted. The cyst diameter used in Tables 2 and 3 was the mean diameter of the cysts measured by the two observers.

The first control group (group 1) was compared to the predialysis films and the second control group (group 2) with the films taken after 10 years of dialysis. The mean age of the patients in group 1 was 45 years (Table 2) and in group 2 it was 56 years (Table 3 ). In the dialysis patients the presence or absence of subperiosteal resorption of the phalanges and terminal tufts was recorded using Meema criteria [18]. The films were examined for the pres-

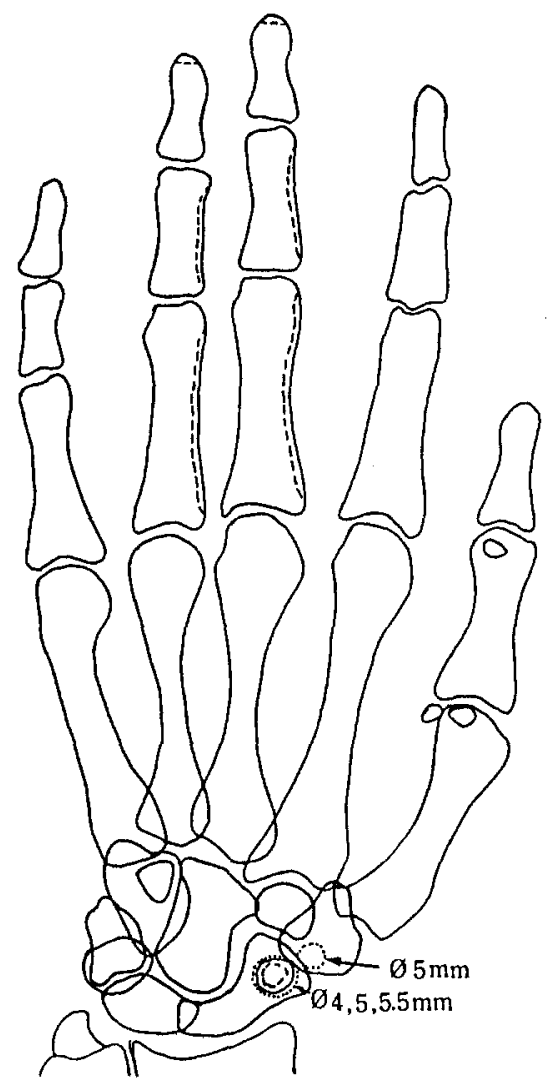

Fig. 1. Mapping of radiological semeiological data. --- Changes after 5 years of dialysis; — changes after 10 years of dialysis; .... changes after 15 years of dialysis; mm: follow-up of diameter of cysts in millimetres

Table 2. Wrist cysts in control group 1 versus patients before dialysis and after 5 years of dialysis

\begin{tabular}{|c|c|c|c|}
\hline & $\begin{array}{l}\text { Control } \\
\text { group } 1\end{array}$ & $\begin{array}{l}\text { Before } \\
\text { dialysis }\end{array}$ & $\begin{array}{l}5 \text { years } \\
\text { dialysis }\end{array}$ \\
\hline Number of patients & 38 & 19 & 20 \\
\hline$\%$ of patients with cysts & $31 \%$ & $27 \%$ & $45 \%$ \\
\hline Mean patient age & 45 years & 45 years & 50 years \\
\hline Mean cyst diameter & $2.7 \mathrm{~mm}$ & $2.9 \mathrm{~mm}$ & $4 \mathrm{~mm}$ \\
\hline $\begin{array}{l}\text { Mean cyst number } \\
\text { per wrist }\end{array}$ & 2 & 2 & 2.5 \\
\hline
\end{tabular}

Table 3. Wrist cysts in control group 2 versus patients after 10 and 20 years

\begin{tabular}{|c|c|c|c|}
\hline & $\begin{array}{l}\text { Control } \\
\text { group } 2\end{array}$ & $\begin{array}{l}10 \text { years } \\
\text { dialysis }\end{array}$ & $\begin{array}{l}20 \text { years } \\
\text { dialysis }\end{array}$ \\
\hline Number of patients & 94 & 20 & 1 \\
\hline$\%$ of patients with cysts & $30 \%$ & $65 \%$ & \\
\hline Mean patient age & 56 years & 55 years & 49 years \\
\hline Mean cyst diameter & $2.4 \mathrm{~mm}$ & $4.7 \mathrm{~mm}$ & $5.2 \mathrm{~mm}$ \\
\hline $\begin{array}{l}\text { Mean cyst number } \\
\text { per wrist }\end{array}$ & 2 & 3.5 & 23 \\
\hline
\end{tabular}

$\mathrm{mm}=$ mean cyst diameter in millimetres 

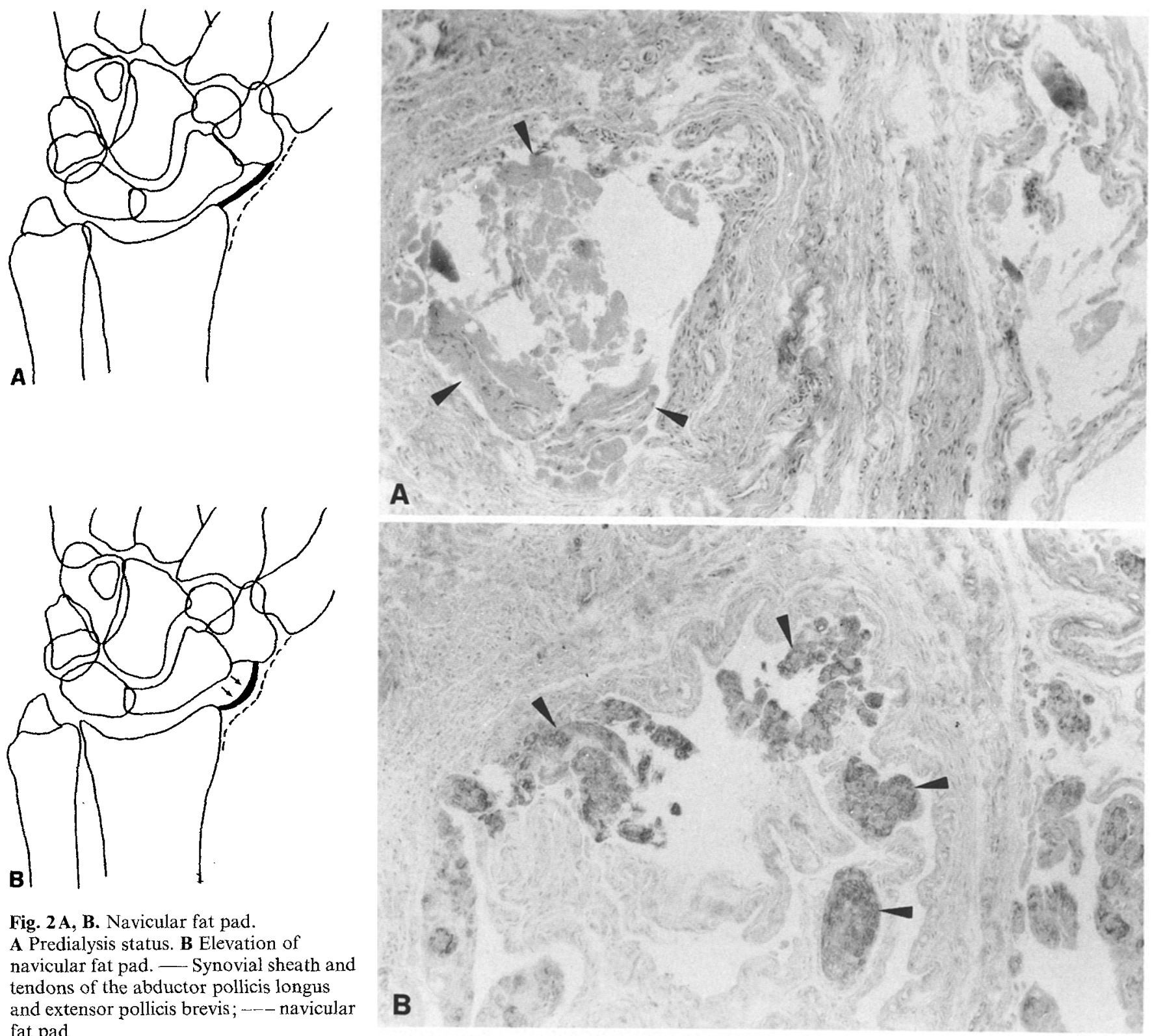

Fig. 2 A, B. Navicular fat pad.

A Predialysis status. B Elevation of navicular fat pad. - Synovial sheath and tendons of the abductor pollicis longus and extensor pollicis brevis; - - navicular fat pad

ence of subchondral cysts in all the joints included in the routine radiological survey. We were able to measure soft tissue swelling around the wrist by using the scaphoid fat pad, around the shoulders by measuring the acromiohumeral distance [26], and in the knees by a sonographic measurement of the total synovial thickness [25].

The wrist measurement taken in each case was the smallest distance between the scaphoid and the lateral edge of the scaphoid fat pad measured at right angles to the long axis of the scaphoid (Fig. 2). The acromiohumeral distance (ACD) was the smallest distance between the most cranial part of the convexity of the humeral head and the concavity of the adjacent acromion. The measurement was done routinely on a supine AP film of the shoulder exposed without tube angulation. In the hip, we studied the iliopsoas and the gluteal fat pads but were unable to make accurate measurements owing to slight differences in positioning during radiography of the pelvis.

The knees of 11 patients were examined by sonography. A standardized technique as described in a previous report was used [25]. Synovial fluid in the suprapatellar bursa was recorded as being present or absent. Total synovial thickness (TST) was measured
Fig. 3A, B. Biopsy material (Patient DK, Table 1). A Congo redstained synovial tissue amyloid deposition in the synovium of the carpus. B Scaphoid cyst curettings containing amyloid deposits strongly staining with beta-2 microglobulin antiserum

in the suprapatellar bursa. $5 \mathrm{MHz}$ (Acuson) and $10 \mathrm{MHz}$ transducers (Diasonics) were used and measurements were made with the electronic calipers. The mean age of this group of patients was 52 years with a range of 38 to 66 years, and the mean duration of dialysis was 14 years, with a range of 11 to 19 years. A control group of nine subjects without knee symptoms was examined, this group averaging 36 years of age with a range of 25-63 years.

Four patients with suprapatellar effusions had fluid aspirated under sonographic guidance and two had synovial biopsy (Table 1). The transverse carpal ligament was biopsied in three patients during a carpal tunnel release operation. In one patient the hip was resected because of collapse, in another we obtained multiple biopsies of the transverse carpal ligament, the synovium of the flexor tendon sheaths, and curetted material from a large cyst in the iunate (Fig. 3). 

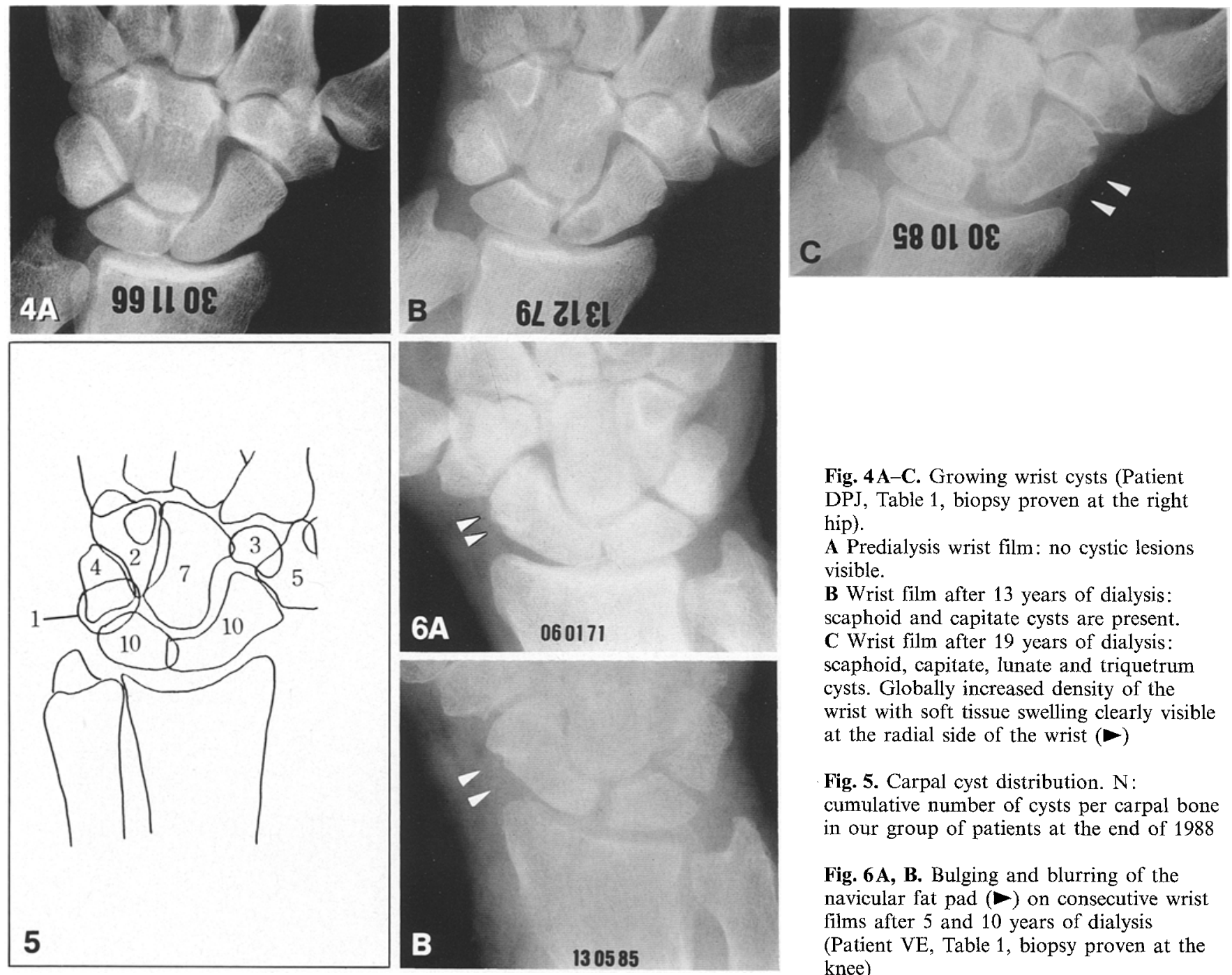

Fig. 4A-C. Growing wrist cysts (Patient DPJ, Table 1, biopsy proven at the right hip).

A Predialysis wrist film: no cystic lesions visible.

B Wrist film after 13 years of dialysis: scaphoid and capitate cysts are present. C Wrist film after 19 years of dialysis: scaphoid, capitate, lunate and triquetrum cysts. Globally increased density of the wrist with soft tissue swelling clearly visible at the radial side of the wrist $(\longrightarrow)$

Fig. 5. Carpal cyst distribution. N : cumulative number of cysts per carpal bone in our group of patients at the end of 1988

Fig. 6A, B. Bulging and blurring of the navicular fat pad ( $)$ on consecutive wrist films after 5 and 10 years of dialysis (Patient VE, Table 1, biopsy proven at the B 130585 knee)

\section{Results}

At the start of dialysis, $27 \%$ of the patients with mean age of 45 years had cysts in the wrist in the absence of other changes of osteoarthritis. The mean number of cysts per wrist was two with an average diameter of $2.9 \mathrm{~mm}$ (Table 2). The control group of adults with the same age ( 45 years) showed cysts in the carpal bones in $31 \%$ of the patients. The mean number of cysts per wrist was two and the mean cyst diameter was $2.7 \mathrm{~mm}$ (Table 2). Films of 20 patients after five years of dialysis, with a mean age of 50 years showed that $45 \%$ had cysts in the wrist with a mean of 2.5 per wrist and mean diameter of $4 \mathrm{~mm}$ (Table 2).

A second control group (mean age 56 years) was compared to the patients dialysed for 10 years. Thirty percent of the patients in the control group had carpal cysts with a mean of two per wrist and mean diameter of $2.4 \mathrm{~mm}$. These results are comparable to the first control group. However, there is an important difference

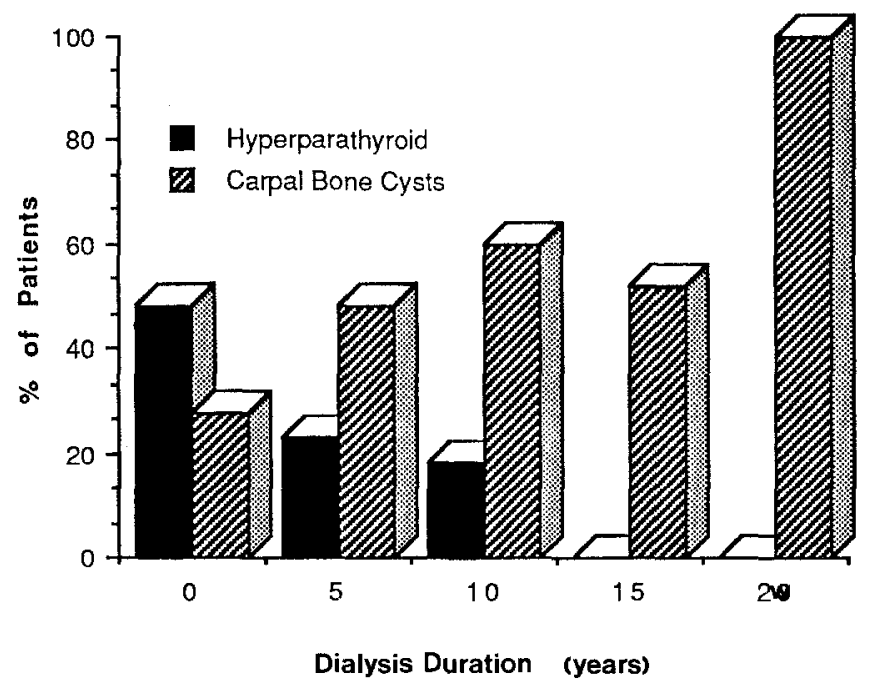

Fig. 7. Hyperparathyroid lesions on hand films versus carpal bone cysts on consecutive films (Table 3 : Hyperparathyroid versus carpal bone cysts) 

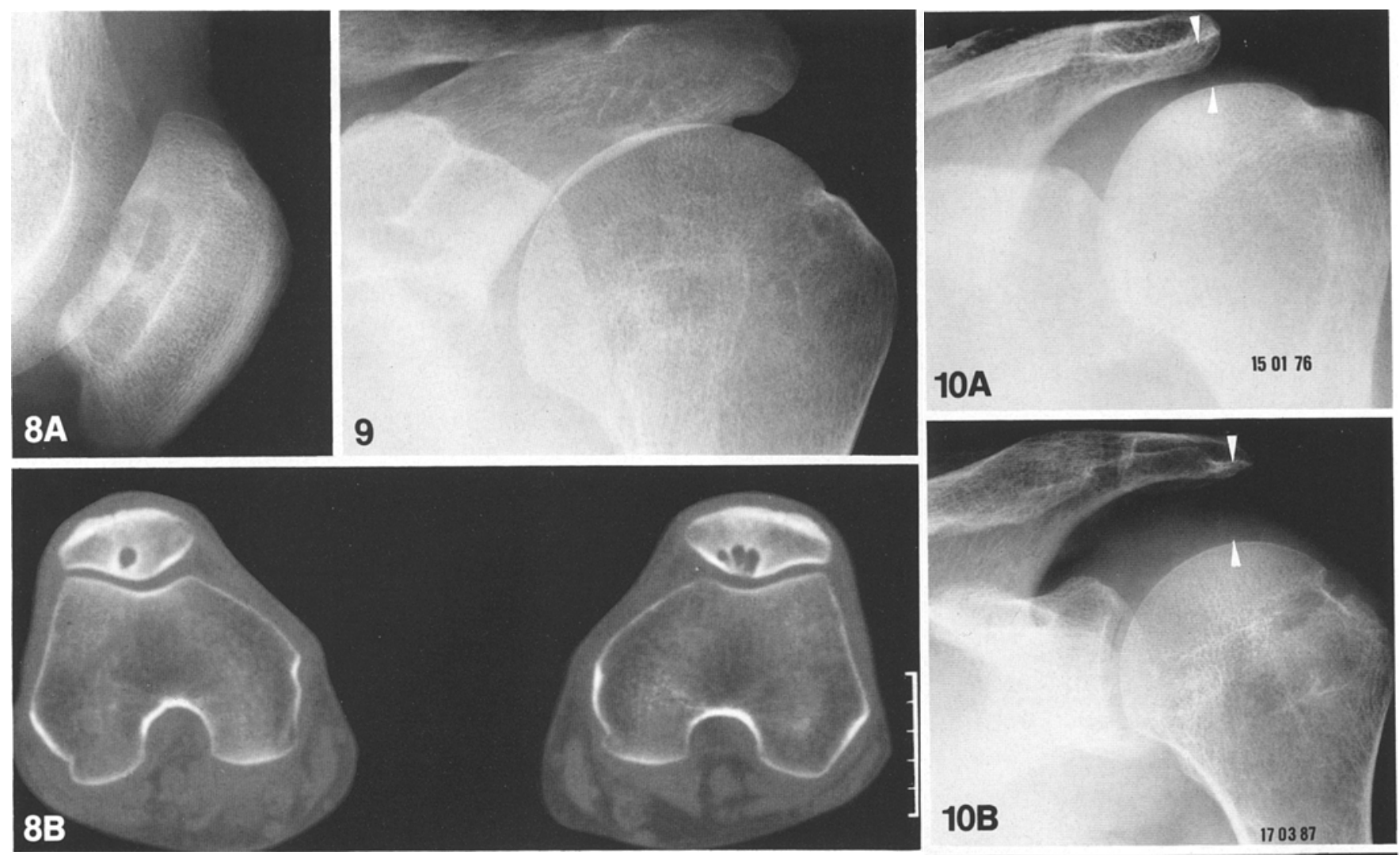

Fig. 8A, B. Patellar cysts (Patient MTh, Table 1, knee aspiration positive for amyloid). A Radiograph of the knee. B Computed tomography of the knees

Fig. 9. Humeral head cysts (Patient JA, Table 1, knee aspiration positive for amyloid)

Fig. 10A, B. Acromiohumeral head distance (ACD) widening (Patient DPJ, Table 1, biopsy proven at the right hip). After 7 and 18 years of dialysis with associated subchondral cysts and vacuum phenomenon in the joint

Fig. 11. Acetabular and femoral neck cysts (Patient LD, Table 1, biopsy proven at the knee)

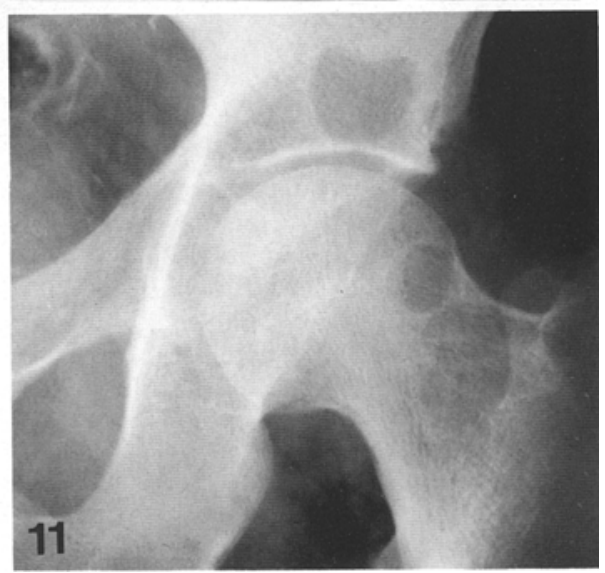

in the number of cysts and their diameter in the group of patients who had dialysis for 10 years: the percentage of patients with cysts was double that of the control group with increased cyst diameter $(4.7 \mathrm{~mm})$ and more cysts per wrist (3.5) (Fig. 4) (Table 3).

The location of carpal cysts at the beginning of dialysis was as follows: one in the capitate, two in the lunate, and four in the scaphoid. At the end of dialysis, the distribution was as follows: seven cysts in the capitate, two in the hamate, five in the trapezium, three in the trapezoid, one in the pisiform, four in the triquetrum, ten in the lunate and in the scaphoid, one in the distal radius and distal ulna (Fig. 5).

At five years there was no change seen in the navicular fat pad. After 10 years, six patients out of 20 showed displacement of the navicular fat pad of $50 \%$ greater than on predialysis films. Four of these patients had enlarging carpal cysts. The navicular fat pad bulged laterally and had blurred margins (Fig. 6). These findings were not present in the control group.

At the start of dialysis, $47 \%$ of the patients had radiological signs of hyperparathyroidism. At five and ten years, the incidence fell to 20 and $15 \%$ respectively (Fig. 7). At five years, enlarging subchondral cysts were noted in the patellas of two patients $(10 \%)$, in five $(25 \%)$ at 10 years (Fig. 8). Enlarging cysts around the shoulder were noted in three patients after five years and in seven patients after 10 years of dialysis (16 and $38 \%$ respectively) (Fig. 9).

There was bilateral increase in ACD of more than $2 \mathrm{~mm}$ in 4 of 18 patients. In these patients subchondral cysts were present bilaterally in one and unilaterally in 

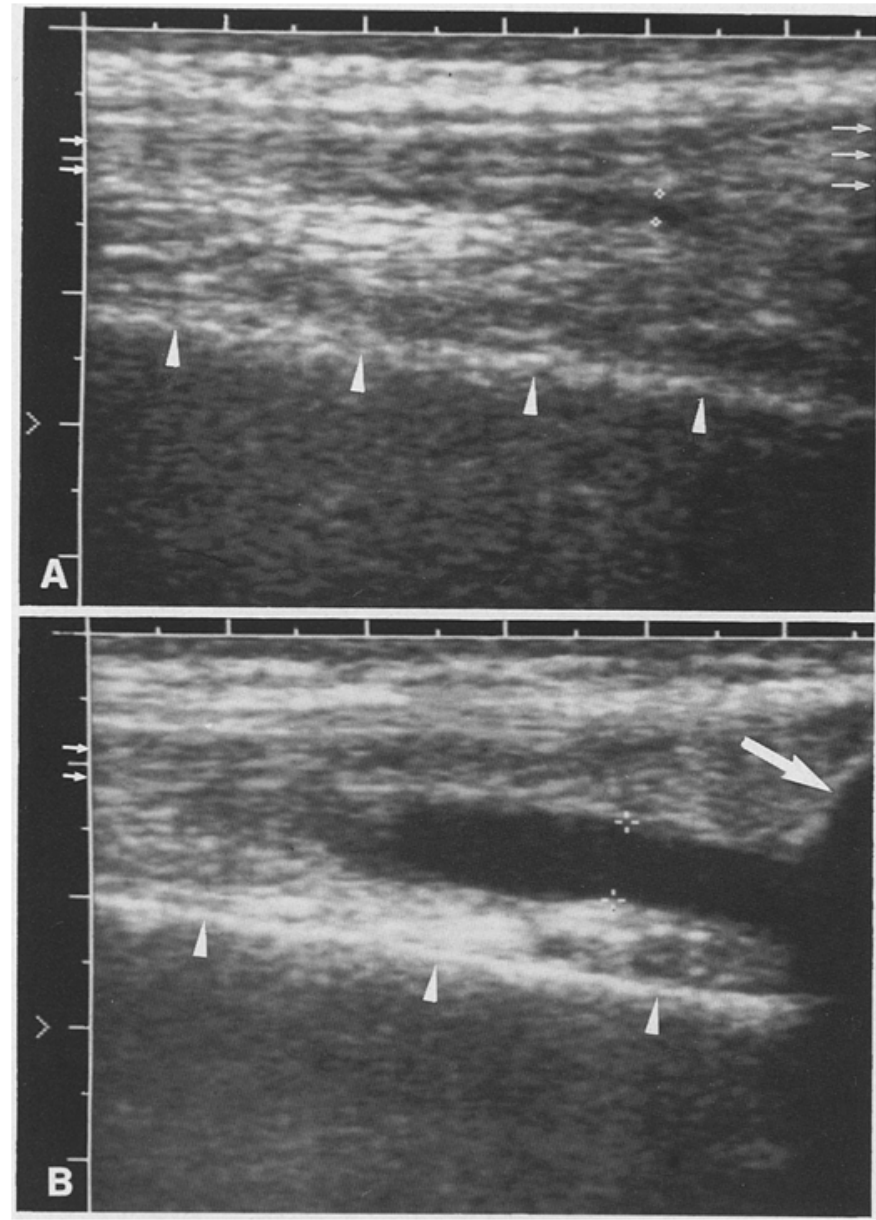

Fig. 12A, B. Sonography of the knee. A Measurement of the antero-posterior diameter of the suprapatellar bursa in a patient without joint swelling and amyloid negative knee aspiration. B Measurement of a fluid-filled suprapatellar bursa in a patient with an amyloid positive knee aspiration. femur; $\rightarrow$ patella; $\rightarrow$ quadriceps muscle tendon. Between the two crosses: extension of the suprapatellar bursa. A No fluid. B Fluid filled suprapatellar bursa

one (Table 4) (Fig. 10). Five patients had subchondral cysts ( 2 unilaterally, 3 bilaterally) with $\mathrm{ACD}$ widening measuring less than $2 \mathrm{~mm}$. Two patients (N.A. and V.B.C. Table 1) with rotator cuff tears and subchondral cysts were excluded. The mean ACD at the start of dialysis was $9.5 \mathrm{~mm}$ with a range of 7 to $12 \mathrm{~mm}$. The mean ACD of our patient group measured at the end of 1988 (mean duration of dialysis $=14$ years) was $13 \mathrm{~mm}$ with a range of 12 to $15 \mathrm{~mm}$. Two patients with rotator cuff tears were excluded.

Subchondral cysts around the hip joints were found in eight patients after 5 years and in ten patients after ten years of dialysis ( 40 and $50 \%$ respectively) (Fig. 11). Analysis of the fat planes around the hips was unreliable. Enlarging cysts were found at at least one of the locations mentioned above in 10 of 20 patients $(50 \%)$ after 5 years of dialysis, in 15 of these patients $(75 \%)$ after 10 years of dialysis and in five of eight patients $(62.5 \%)$ after 15 years of dialysis. The only patient who has had dialysis for over 20 years had multiple large cysts in his wrists, shoulders, and hips in addition to marked clinically palpable soft tissue swelling around the joints.

Sonography of both knees was performed in 11 patients not showing evidence of arthritis on plain films. Suprapatellar effusions were present in 19 knees. The mean TST in these knees was $4.7 \mathrm{~mm}$ with a range of 0-6 mm. In our control group of 18 asymptomatic knees, no fluid was found and the mean synovial thickness was $0.3 \mathrm{~mm}$ (range 0-2 mm) (Fig. 12A).

Suprapatellar bursal aspiration in four patients showed amyloid to be present in three (Table 1). The TST was $2.8,3.4$, and $4.2 \mathrm{~mm}$ in the patients with amyloid and $1 \mathrm{~mm}$ in the patient without. In the two patients having synovial biopsy of the knee, the B2-microglobulin test was positive. The TST in these two patients was $4.5 \mathrm{~mm}$ and $6 \mathrm{~mm}$ (Fig. 11B). One of the patients with synovial fluid positive for amyloid had subchondral cysts in the patella, but the other two had none, although they had subchondral cysts in other joints. Only one of the patients with a positive synovial biopsy in the knee had large subchondral cysts in the patella and the femoral condyle. The other patient had cysts in other joints. Biopsy of the transverse carpal ligament in four patients during carpal tunnel release showed B2-specific amyloid. Two of these patients had enlarging cysts in the wrist, a third had them in the right hip and shoulder, the fourth one had only one cyst in the left humeral head. In one patient biopsies were obtained from the transverse carpal ligament, the synovium of the flexor tendon sheath and from a cyst in the scaphoid. These biopsies all showed B2 microglobulin-positive amyloid.

\section{Discussion}

The radiographs of our hemodialysis patients showed lesions similar to those previously described in amyloidosis of bone. This study showed subchondral cysts and large punched-out erosions which increased in size and number as the duration of hemodialysis increased. The capitate, lunate and scaphoid were most often involved. Progressive soft tissue swelling associated with the bony changes was measured on plain films of the wrist and shoulder and by ultrasonography of the knee. Ultrasonography showed that the soft tissue swelling was due to a combination of fluid and synovial thickening. Sonography is probably a sensitive method for the detection of bone and joint amyloidosis in dialysis patients. All five patients with amyloid in the knees had thickening of the synovium in the suprapatellar bursa, although only two had bone changes. One asymptomatic control patient had normal synovial thickness and no amyloid. Further investigation of the technique will show if the synovial thickening in dialysis patients is due to amyloid deposition.

It should be emphasized that whereas the signs of hyperparathyroidism decreased with time, size and the number of the subchondral cysts increased. Furthermore, their small size and periarticular location would be unlike brown tumors. Biopsy of these cysts and the 
evidence of previous reports $[1,3,4,6,7,9,13,14$, $19,26]$ in the literature indicate amyloid deposition in bone. Identical lesions have been described in primary amyloidosis with bone and joint involvement.

In primary bone and joint amyloidosis, the dominant clinical finding is carpal tunnel syndrome $(30-50 \%$ of the patients). In dialysis-related amyloid the frequency of carpal tunnel syndrome is high. All of the patients in this series had at least one carpal tunnel syndrome, six of them had a carpal tunnel release operation. The amyloidosis secondary to hemodialysis is a very specific type consisting of B2-microglobulin $[4,7,9,17]$ and occurs mainly in bones and synovium of joints. The joints most commonly involved are the wrist, shoulder and hip. The knee is less frequently involved. B2-specific amyloid was present in all the synovial biopsy specimens obtained from seven patients. Amyloid was detected in the joint fluid of three symptomatic knees, but there was not enough amyloid present to determine the type.

Bone and joint amyloid develops in both bone and soft tissue. It has been suggested that the deposition begins in the synovium but there is no evidence to support this hypothesis. Observation of the cysts in the wrists of patients in this series showed that pre-existing (predialysis) cysts were enlarging. This may be due to deposition of amyloid in synovial lining of the pre-existing cyst. Alternatively, amyloid deposition in synovium may predate the invasion of the cyst.

The differential diagnosis of arthritis in patients on long-term hemodialysis includes hydroxyapatite and calcium pyrophosphate deposition diseases or secondary oxalosis. These diseases typically have soft tissue calcification $[5,20,23]$ which distinguishes them from amyloid bone disease occurring in dialysis patients where soft tissue calcification is absent.

\section{References}

1, Assenat H, Calemard E, Charra B, Laurent G, Terrat JC, Vanel $T$ (1980) Hemodialyse, syndrome du canal carpien et substance amyloide. Nouv Presse Med 9:1715

2. Axelsson U, Hallen A, Rausing A (1970) Amyloidosis of bone. Report of two cases. J Bone Joint Surg [Br] 52:717

3. Bardin T, Kuntz D, Zingraff J, Voisin M-C, Zelmar A, Lansaman J (1985) Synovial amyloidosis in patients undergoing longterm hemodialysis. Arthritis Rheum 28:1052

4. Bardin T, Zingraff J, Shirahama T (1987) Hemodialysis-associated amyloidosis and beta-2 microglobulin: Clinical and immunohistochemical study. Am J Med 83:419

5. Braunstein EM, Menery K, Martel W, Swartz R, Fox IH (1987) Radiologic features of a pyrophosphate-like arthropathy associated with long-term dialysis. Skeletal Radiol 16:437

6. Brown EA, Arnold IR, Gower PE (1986) Dialysis arthropathy: Complication of long-term treatment with hemodialysis. $\mathrm{Br}$ Med J 292:163

7. Chanard J, Lavaud S, Toupange D, Melin JP, Gillery P, Revillard JP (1986) Beta 2-microglobulin-associated amyloidosis in chronic hemodialysis patients. Lancet 1:1212

8. Dahlin DC (1950) Classification and general apsects of amyloidosis. Med Clin North Am 34:1107

9. Fuchs A, Jagirdar J, Schwartz IS (1987) Beta 2-microglobulin amyloidosis (AB2M) in patients undergoing long-term hemodialysis. Am J Clin Pathol 88:302

10. Gardner H (1961) Bone lesions in primary systemic amyloidosis: Report of a case. Br J Radiol 34:778

11. Grigon B, Regent D, Pere P, Kessler M, Netter P, Gaucher A (1987) Manifestations osteo-articulaires des hemodialyses chroniques. Aspects actuels. Feullets Radiol 27:411

12. Grossman RE, Henseley GT (1967) Bone lesions in primary amyloidosis. AJR 101:872

13. Huaux JP, Noel H, Malghem J, Maldague B, Devogelaer JP, Nagant De Deuxchaisnes (1985) Erosive azotemic osteoarthropathy, possible role of amyloidosis. Arthritis Rheum $28: 1075$

14. Kaplan P, Resnick D, Murphey M, Heck L, Phalan DJ, Egan D, Rutsky E (1987) Destructive noninfectious spondylarthropathy in hemodialysis patients: A report of four cases. $\mathrm{Ra}$ diology 162:241

15. Koletsky S, Stecher RM (1939) Primary systemic amyloidosis: Involvement of cardiac valves, joints and bones with pathologic fractures of femur. Arch Pathol Lab Med 27:267

16. Kuntz D, Naveau B, Bardin T, Drueke T, Treves R, Dryll A (1984) Destructive spondylarthropathy in hemodialysed patients. Arthritis Rheum 27:369

17. Lambrey G, Sebert JL, Bardin T, Shirahama T, Marie A, Gheerbrand JD, Moriniere P, Kuntz D, Zingraff J, Fournier A (1986) Destructive spondylarthropathy of hemodialysis patients is associated with amyloidosis reacting with anti-beta 2 macroglobulin antiserum. Proc Eur Dial Transplant Assoc $23: 139$

18. Meema HE, Oreopoulos DG, Murray TM (1986) Periosteal resorption and periosteal neostosis: Comparison of normal subjects and renal failure patients on chronic ambulatory peritoneal dialysis using MOP-3 image analysis system and a grading method. Skeletal Radiol 15:14

19. Munoz-Gomez J, Bergada-Barado E, Gomez-Perez R, LlopartBuisan E, Subias-Sobrevia E, Rotes-Querol J, Sole-Arques (1985) Amyloid arthropathy in patients undergoing periodical hemodialysis for chronic renal failure: A new complication. Ann Rheum Dis 44: 729

20. Reginato AJ, Ferreiro-Seoane JL, Alvarez CB, Piferrer JM, Clayburne G, Rothfuss S (1986) Arthropathy and cutaneous calcinosis in hemodialysis oxalosis. Arthritis Rheum 29:1387

21. Resnick D, Niwayama G (1988) Diagnosis of bone and joint disorders, 2nd edn. Saunders, Philadelphia, p 2387

22. Subbarao K, Jacobson HG (1986) Amyloidosis and plasma cell dyscrasias of the musculoskeletal system. Semin Roentgenol $21: 139$

23. Sundaram M, Wolverson MK, Heiberg E, Grider RD (1981) Erosive azotemic osteodystrophy. AJR 136:363

24. Vandenbroucke JM, Jadoul M, Maldague B, Huaux JP, Noel H, Van Ypersele De Strihou C (1986) Possible role of dialysis membrane characteristics in amyloid osteoarthropathy. Lancet $1: 1210$

25. van Holsbeeck M, van Hosbeeck K, Gevers G, Marchal G, Van Steen A, Favril A, Gielen J, Nijs J, Dequeker J, Baert A (1988) Staging and follow-up of rheumatoid arthritis of the knee. Comparison of sonography, thermography and clinical assessment. J Ultrasound Med 7:561

26. Van Ypersele de Strihou C, Honhon B, Vandenbroucke JM, Huaux JP, Noel H, Maldague B (1987) L'Amylose du dialysé. Flammarion Medicine-sciences. Actualités Néphrologiques, Paris, p 372

27. Weinfeld A, Stern MH, Marx LH (1970) Amyloid lesions of bone. AJR 108:799

28. Wendling D, Guidet M (1986) Manifestations articulaires et periarticulaires de l'hemodialyse chronique chez l'adulte. Rev Rhum Mal Osteoartic 53:715

29. Köhler A, Zimmer EA (1982) Grenzen des Normalen und Anfänge des Pathologischen im Röntgenbild des Skeletts. Thieme, Stuttgart New York, p 145 